\title{
INTEGRASI METODE FUZZY ADDITIVE SVM (FASVM) MENGGUNAKAN MODEL WARNA YUV-CMY-HSV UNTUK KLASIFIKASI BIBIT UNGGUL SAPI BALI MELALUI CITRA DIGITAL
}

\author{
Imam Cholissodin $^{1}$, Arief Andy Soebroto ${ }^{1}$, Nurul Hidayat ${ }^{1}$ \\ ${ }^{1}$ Fakultas Ilmu Komputer, Universitas Brawijaya \\ Email: 1imamcs@ub.ac.id, ${ }^{2}$ ariefas@ub.ac.id, ${ }^{3}$ ntayadih@ub.ac.id
}

(Naskah masuk: 11 Juni 2015, diterima untuk diterbitkan: 22 Juli 2015)

\begin{abstract}
Abstrak
Budidaya sapi sangat identik dengan pemilihan bibit unggul, namun permasalahan yang sering muncul adalah cara mengenali bibit unggul tersebut yang relatif tidak mudah, cenderung membutuhkan waktu cukup lama. Peternak masih sering mengamati warna kulit dengan mata secara langsung, yang cenderung kurang teliti. Sehingga dalam penelitian ini, diusulkan metode dengan menggunakan beberapa model warna yang nantinya sebagai rekomendasi untuk fitur yang optimal dalam sistem. Kemudian metode klasifikasi yang digunakan adalah Fuzzy Additive Support Vector Machine (FASVM). Data yang digunakan didapatkan dari Balai Pembibitan Ternak Unggul (BPTU) Sapi Bali. Dari hasil pengujian didapatkan model warna yang paling optimal dan rata-rata akurasi pada Sapi Betina dan Jantan dengan ukuran citra tertentu. Model warna tersebut sangat dipengaruhi oleh kondisi data citra dan juga banyaknya kelas data.
\end{abstract}

Kata kunci: Sapi Bali, Model warna, Intersection kernel, Fuzzy additive SVM, Sequential training SVM

\begin{abstract}
Cattle farming is identical with the selection of seeds, but the problems that often arises is how to recognize quality seeds are relatively easy, tend to take a long time. Breeders still often observe skin color with eyes directly, which tend to be less rigorous. Thus, in this study, the proposed method by using several color models that will be voted on features that are optimal in the system. Then the classification method used is Additive Fuzzy Support Vector Machine (FASVM). The data used was obtained from Livestock Breeding Center for Excellence (BPTU) Bali cattle. From the test results obtained the most optimal color models and average accuracy on Cow Females and Males with a particular image size. The color model is highly influenced by the condition of the image data and also the amount of class data.
\end{abstract}

Keywords: Bali cattle, Color model, Intersection kernel, Fuzzy additive SVM, Sequential training SVM

\section{PENDAHULUAN}

Sapi Bali secara umum memiliki khas warna cokelat, yang mudah digunakan untuk identifikasi kualitas, sekaligus untuk mengetahui adanya indikasi penyimpangan. Identifikasi Sapi Bali tersebut diklasifikasi ke dalam tiga kelas yaitu kualitas sangat baik, sedang dan buruk berdasarkan model warna dari data citra menggunakan suatu sistem cerdas. Tempat penelitian berada pada Balai Pembibitan Ternak Unggul (BPTU) Sapi Bali.

Kernel Additive sering dibuat untuk identifikasi citra yang memberikan hasil lebih baik dan signifikan pada banyak dataset yang sama dibandingkan dengan kernel sebelumnya (Subhransu Maji, Alexander C. Berg, Jitendra Malik, 2013). Penelitian tersebut menguji pada berbagai dataset skala besar dan bersifat realtime, yang terbukti mampu untuk mempercepat pada saat proses pelatihan. Penelitian SVM lainnya yang juga setara, yaitu konsep Multiple
Kernel Learning (MKL), yang sangat baik jika diimplementasikan pada data sangat heterogen. Dalam MKL, yang menjadi masalah utama adalah harus dapat mengoptimalkan dua koefisien yaitu lagrange multiplier dan bobot kernel. Dan MKL juga membutuhkan waktu komputasi yang cukup besar pada proses pembelajaran dan sulit untuk diterapkan (I-Hong Jhuo, dan D. T. Lee, 2010). Data yang digunakan dalam penelitian yang diusulkan ini bersifat homogen, yaitu data satu jenis Sapi Bali yang dibedakan kualitasnya antara Jantan dan Betina dalam tiga kelas. Meskipun bisa menggunakan MKL, namun terdapat dua hal yang menjadi benang merah yaitu dari karakteristik datanya yang kurang tepat dan juga efisiensi waktu komputasinya yang tinggi. Kemudian terdapat pula metode Relevance Vector Machine (RVM), namun diketahui bahwa metode ini sangat lambat pada dataset yang sangat besar dikarenakan waktu komputasi proses pelatihannya yang tinggi dibandingkan SVM secara umum (Michael E. Tipping, 2000). Sedangkan, Kernel 
Additive sudah terbukti secara signifikan lebih cepat dari SVM dengan kernel secara umumnya. Misal pada dataset Daimler-Chrysler pedestrians, dari hasil pengujian Subhransu Maji (2013) diperoleh bahwa Kernel Additive lebih cepat puluhan ribu kali dari pada Kernel Linier dan RBF dengan hasil akurasi yang paling optimal pula. Kemudian pada penelitian lainnya, Takuya Inoue dan Shigeo Abe (2001) mengusulkan metode Fuzzy Support Vector Machine (FSVM) menggunakan decision functions untuk menyelesaian regions yang tidak bisa diklasifikasikan dengan SVM pada data yang kurang heterogen. Hal ini sangat sesuai dengan data yang digunakan pada penelitian ini.

Pada penelitian ini diusulkan teknik integrasi metode fuzzy dengan Kernel Additive SVM. Fitur data citra yang telah diambil, kemudian diolah menggunakan beberapa model warna yang kemudian diproses dengan metode Fuzzy Additive Support Vector Machine (FASVM).

\section{TINJAUAN PUSTAKA}

\subsection{Sapi Bali}

Sapi Bali merupakan hasil domestikasi dari banteng yang terjadi sebelum $3.500 \mathrm{SM}$, yang juga terjadi pada wilayah Pulau Jawa dan Lombok. Populasinya saat ini ditaksir sekitar 526.031 ekor. Kemurnian genetika Sapi Bali dilindungi oleh Peraturan Gubernur Bali Nomor 45 Tahun 2004 dan Perda No 2/2003 yang melarang bibit Sapi Bali Betina keluar dari wilayah provinsi ini (Peraturan Gubernur Bali Nomor 45, 2004) dan (Perda Nomor 2, 2003).
Baik
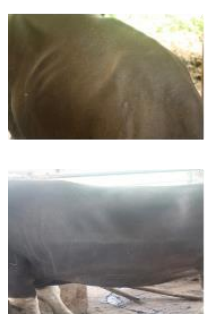

Sedang
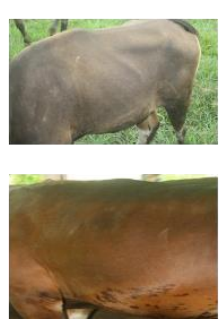

Buruk
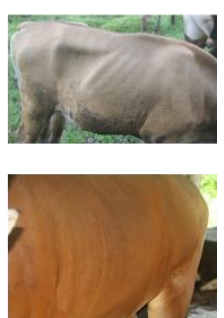

Gambar 1 Kualitas Sapi di Bali dari Citra Digital

Sumber : Balai Pembibitan Ternak Unggul Sapi Bali (2013)

Beberapa degradasi genetik telah ditemukan pada Sapi rakyat, yaitu warna tubuh sampai bulu telinga bagian dalam berwarna hitam sejak kecil. Kemudian, pada Sapi Jantan walaupun dikebiri tidak terjadi perubahan warna. Terdapat pula Sapi mores yaitu adanya warna hitam atau merah pada bagian bawah yang mestinya berwarna putih (Soekardono, Chairussyhur Arman, dan Lalu Muhammad Kasip, 2009).

\subsection{Bibit Unggul}

Standar mutu bibit Sapi potong seperti terdapat dalam Peraturan Menteri Pertanian Nomor: 54/Permentan/OT.140/10/2006 tanggal 20 Oktober 2006, tentang Pedoman Pembibitan Sapi Potong yang baik (good breeding practice). Proses pengembangan bibit induk dapat dilihat pada Standar mutu Sapi Bali bibit (Soekardono, Chairussyhur Arman, dan Lalu Muhammad Kasip, 2009).

Pada tahun sebelumnya, Ni Wayan Patmawati dkk melakukan penelitian tentang pemilihan bibit unggul Sapi Bali dari hasil seleksi sapi pejantan berbasis uji Performans. Berdasakan hasil uji, didapatkan tiga jenis performans terbaik (Ni Wayan Patmawati dkk, 2013).

\subsection{Citra Digital}

Citra digital adalah citra fisik yang telah dilakukan proses digitalisasi dengan teknik dan ukuran tertentu. Nilai $f$ di koordinat $(x, y)$ pada Gambar 2 menunjukkan intensitas warna tertentu citra yang nantinya dapat dimanfaatkan untuk analisis (Rafael C. Gonzalez, Richard E. Woods, 2008), dan sekaligus menggunkankan model warna, misal YUV (Zaher Hamid Al-Tairi dkk., 2014), CMY, HSV (Noor A. Ibraheem dkk., 2012).

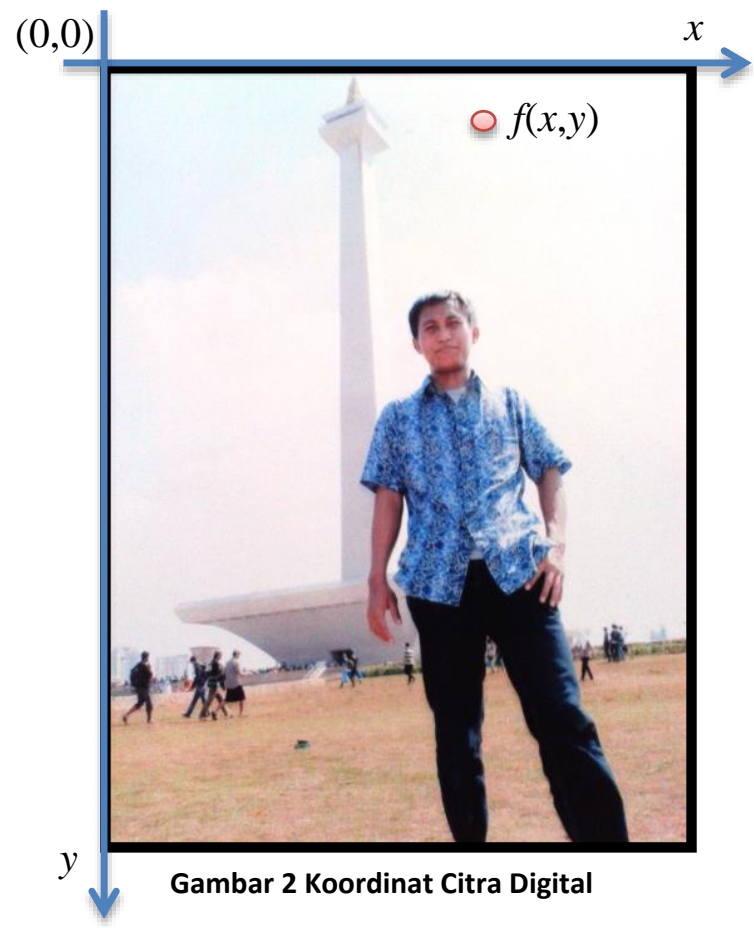

\subsection{Additive Kernel SVM}

Formulasi SVM untuk kasus linear maupun non-linear, yaitu bagaimana dapat menemukan hyperplane terbaik yang memisahkan data dengan optimal (C. Cortes., V. Vapnik, 1995). $f(x)$ sebagai fungsi keputusan hasil klasifikasi yang dapat ditulis dengan $f(x)=w \bullet x+b$. Jika pada kasus non- 
linear ditulis $f(x)=w \bullet \varphi(x)+b \quad$ (Subhransu Maji, Alexander C. Berg, Jitendra Malik, 2013).

Kernel Additive merupakan kernel non-linear pada SVM, dimana fungsi kernel $\mathrm{K}\left(\mathrm{x}, \mathrm{x}_{\mathrm{i}}\right)$ dan persamaan hyperplane $f(x)$ diubah menjadi

$$
f(x)=\sum_{i=1}^{n} f_{i}\left(x_{i}\right)+b
$$

dan jika persamaan (1) dijabarkan lagi, maka akan didapatkan persamaan (2).

$$
f_{i}\left(x_{i}\right)=\sum_{l=1}^{m} \alpha_{l} y_{i} K_{i}\left(x_{i}, x_{l, i}\right)
$$

$x_{l, i}$ merupakan data ke- $l$ pada kernel ke-i. Salah satu kernel yang termasuk Kernel Additive yaitu Intersection Kernel. Pada persamaan (3), $x_{i}$ merupakan data dimensi ke- $i$.

$$
f_{i}\left(x_{i}\right)=\sum_{x_{l, i}<s_{i}} \alpha_{l} y_{l} x_{l . i}+x_{i} \sum_{x_{l, i} \geq s_{i}} \alpha_{l} y_{l}
$$

Pada Intersection Kernel, nilai $b$ dihitung dengan persamaan (4) dan (5).

$$
\begin{aligned}
& b=-\frac{1}{2}\left[\left(\sum_{i=1}^{m} \alpha_{i} y_{i} x_{i} \bullet x^{+}\right)+\right] \\
& b=-\frac{1}{2}\left[\left(\sum_{i=1}^{m} \alpha_{i} y_{i} x_{i} \bullet x^{-}\right)\right] \\
& {\left[\left(\sum_{i=1}^{m} \alpha_{i} y_{i} \sum_{i=1}^{n} \min \left(x_{i}, x^{+}\right)\right)+\right]} \\
& \left.\sum_{i=1}^{n} y_{i} \sum_{i=1}^{n} \min \left(x_{i}, x^{-}\right)\right]
\end{aligned}
$$

\subsection{Fuzzy Support Vector Machine (SVM)}

Pada Gambar 3, bagian ruang yang merupakan irisan, adalah daerah yang sulit untuk diklasifikasikan. Dari hal tersebut, maka perlu fungsi keanggotaan fuzzy menggunakan persamaan (6) dan (7) untuk mendapatkan hasil klasifikasi data yang memenuhi $D_{i}(x)=w_{i}^{t} x+b_{i}>0$. Dalam hal ini, kelas $i$ didefinisikan satu dimensi fungsi keanggotaan $m_{i j}(x)$ pada arah ortogonal untuk memisahkan hyperplanes $D_{j}(x)=0$ (Takuya Inoue, dan Shigeo Abe, 2001) :

\section{Untuk $\mathbf{i}=\mathbf{j}$}

$$
m_{i i}(x)=\left\{\begin{array}{llr}
1 & \text { untuk } & D_{i}(x)>1 \\
D_{i}(x) & \text { lainnya }
\end{array}\right.
$$

2. Untuk $\mathbf{i} \neq \mathbf{j}$

$$
m_{i j}(x)=\left\{\begin{array}{lrr}
1 & \text { untuk } & D_{j}(x)<-1 \\
-D_{j}(x) & \text { lainnya }
\end{array}\right.
$$

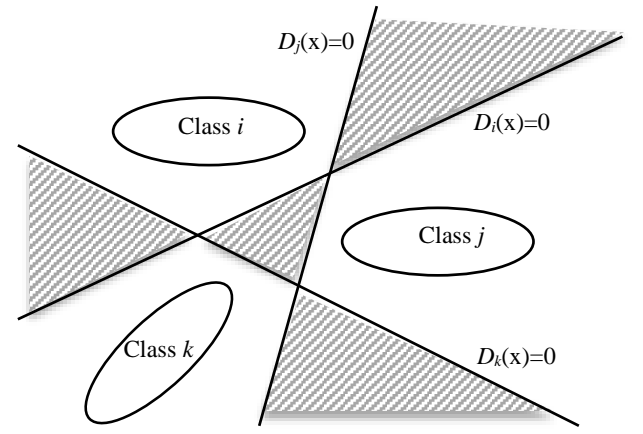

Gambar 3 Region Yang Tidak Bisa Diklasifikasi Dengan 2 Kelas

\section{HASIL PENGUJIAN DAN ANALISIS}

Dalam penelitian ini menggunakan skenario pengujian terhadap ukuran cropping citra, yaitu 32px, 64px, 128px dan rasio perbandingan data latih dan data uji pada Sapi Bali Betina dan Jantan dengan nilai parameter Lamda $=5, C=1$, IterMax $=100000$, dan Epsilon $=10^{-5}$.

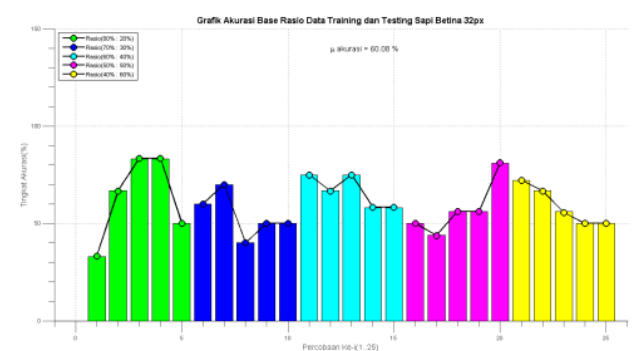

Gambar 4 Grafik Akurasi Sapi Betina 32px (YUV)

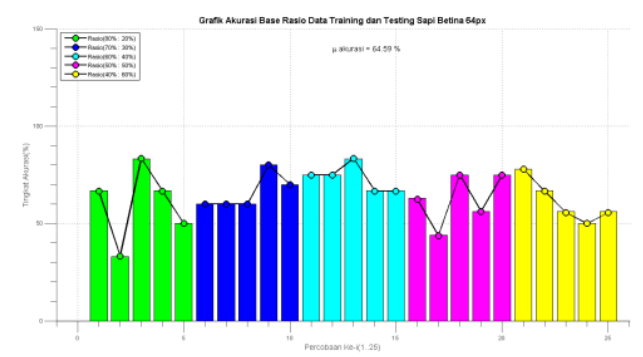

Gambar 5 Grafik Akurasi Sapi Betina 64px (YUV)

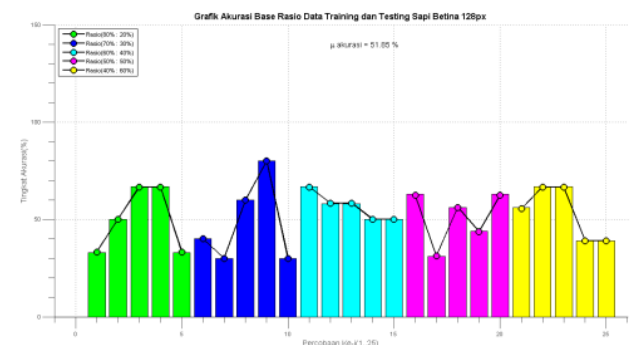

Gambar 6 Grafik Akurasi Sapi Betina 128px (YUV) 
Imam Cholissodin, Integrasi Metode Fuzzy Additive SVM (FASVM) Menggunakan Model Warna YUV-CMY-HSV... 113

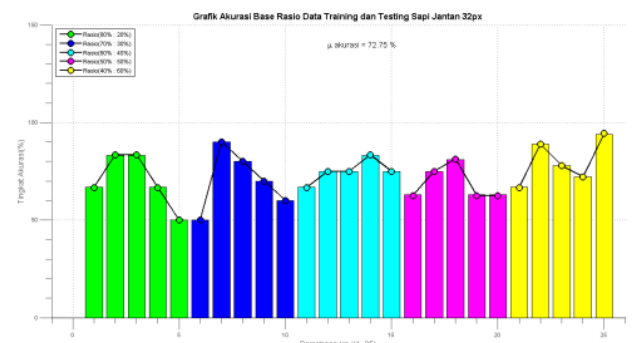

Gambar 7 Grafik Akurasi Sapi Jantan 32px (YUV)

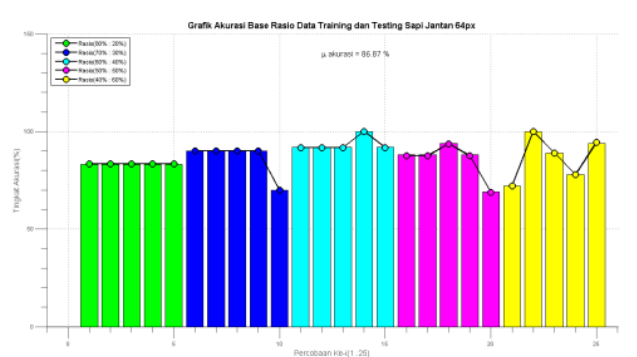

Gambar 8 Grafik Akurasi Sapi Jantan 64px (YUV)

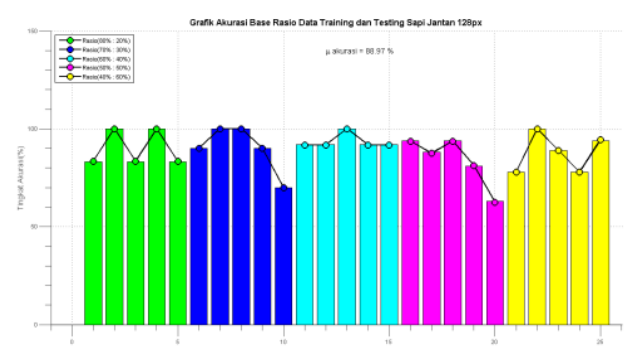

Gambar 9 Grafik Akurasi Sapi Jantan 128px (YUV)

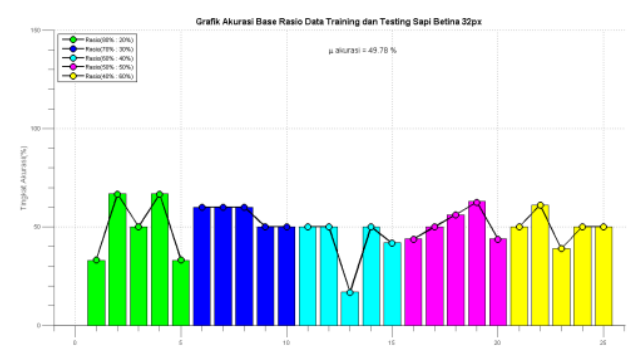

Gambar 10 Grafik Akurasi Sapi Betina 32px (CMY)

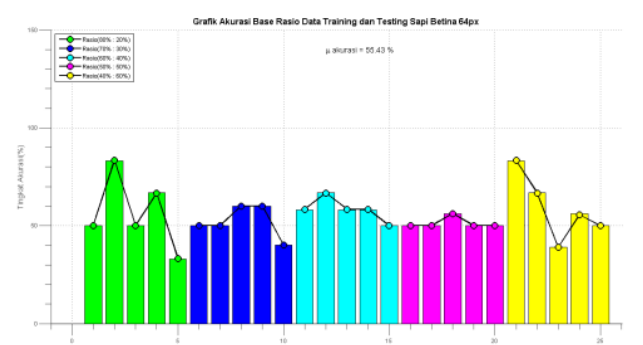

Gambar 11 Grafik Akurasi Sapi Betina 64px (CMY)

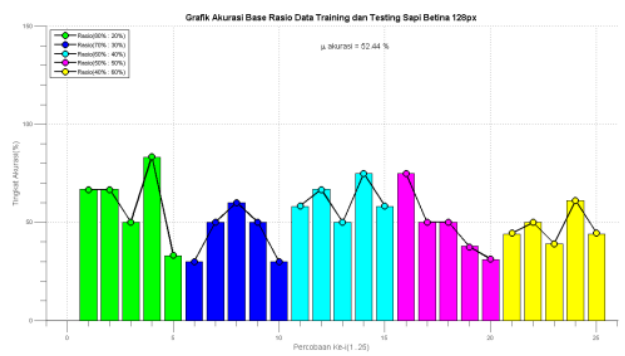

Gambar 12 Grafik Akurasi Sapi Betina 128px (CMY)

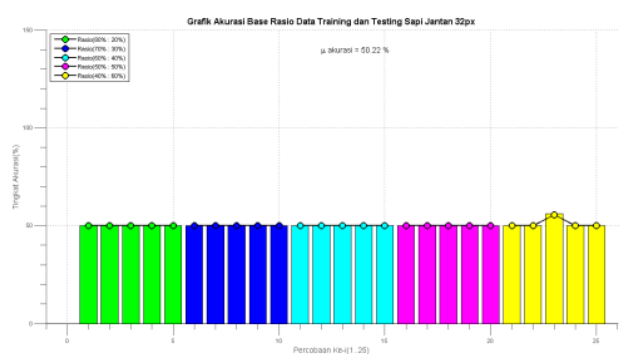

Gambar 13 Grafik Akurasi Sapi Jantan 32px (CMY)

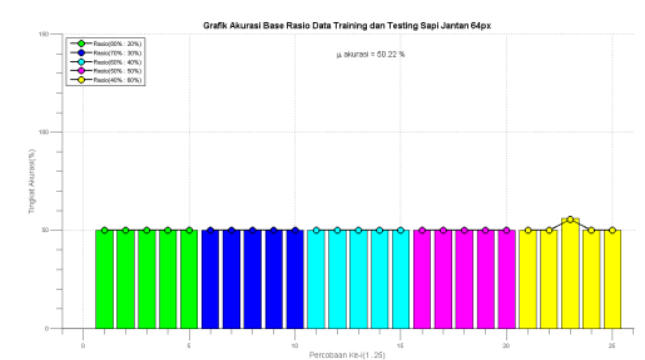

Gambar 14 Grafik Akurasi Sapi Jantan 64px (CMY)

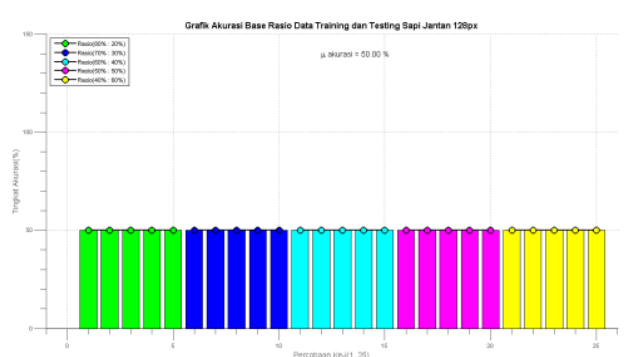

Gambar 15 Grafik Akurasi Sapi Jantan 128px (CMY)

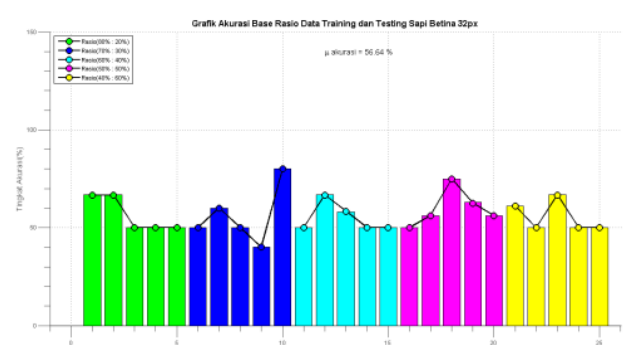

Gambar 16 Grafik Akurasi Sapi Betina 32px (HSV) 


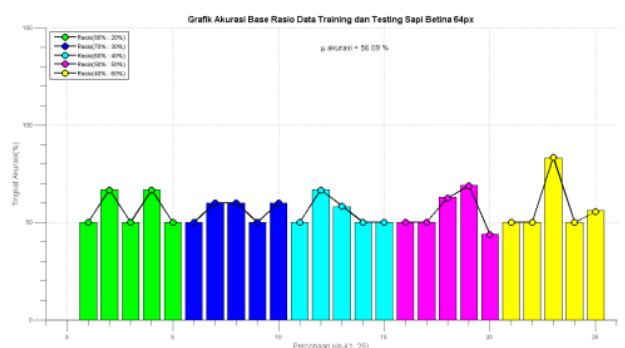

Gambar 17 Grafik Akurasi Sapi Betina 64px (HSV)

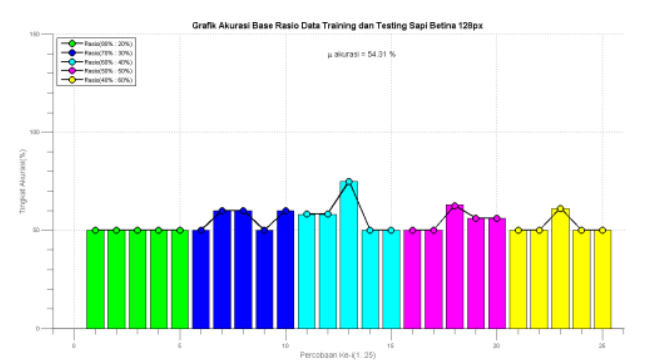

Gambar 18 Grafik Akurasi Sapi Betina 128px (HSV)

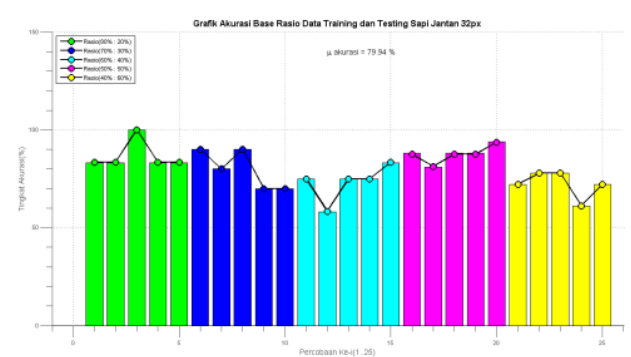

Gambar 19 Grafik Akurasi Sapi Jantan 32px (HSV)

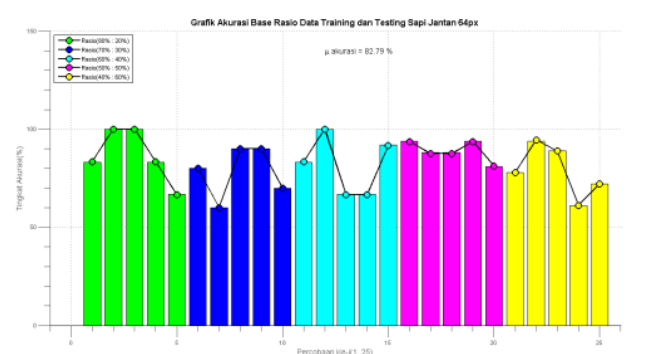

Gambar 20 Grafik Akurasi Sapi Jantan 64px (HSV)

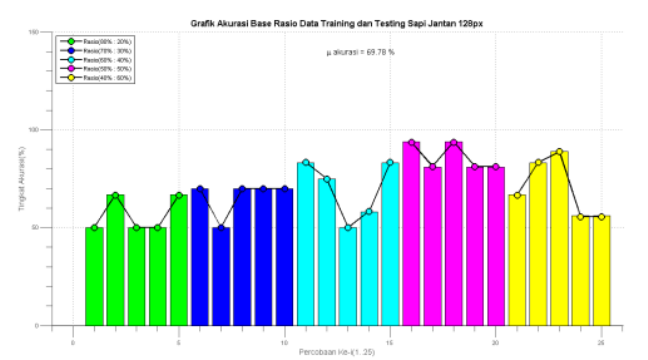

Gambar 21 Grafik Akurasi Sapi Jantan 128px (HSV)
Hasil analisis dari pengujian Sapi Betina seperti yang ditunjukkan pada Gambar 5 didapatkan hasil rata-rata akurasi tertinggi sebesar $64.59 \%$ pada ukuran cropping citra 64px dengan model warna YUV. Namun secara umum, dapat disimpulkan bahwa pada hampir semua nilai akurasi data Sapi Betina, nilainya tidak begitu optimal. Hal ini sangat dipengaruhi oleh kemiripan warna untuk setiap kelas dan perbedaan polanya tidak signifikan. Sedangkan hasil pengujian Sapi Jantan, didapatkan rata-rata nilai akurasi tertinggi sebesar $88.97 \%$ pada ukuran cropping citra 128px dengan model warna YUV. Hal ini dapat disimpulkan bahwa hasil pencapaian pengujian citra pada Sapi Jantan cukup optimal.

\section{KESIMPULAN DAN SARAN}

\section{Kesimpulan}

1. Integrasi FASVM dengan menggunakan model warna dapat digunakan untuk klasifikasi data citra Sapi pada 3 (tiga) kelas, mulai dari proses training untuk membentuk 3 (tiga) hyperplane. Kemudian dilakukan pengujian terhadap masing-masing hyperplane tersebut untuk mendapatkan nilai keanggotaan dari nilai fungsi klasifikasinya.

2. Hasil beberapa proses pengujian kinerja algoritma yang diusulkan didapatkan rata-rata akurasi pada Sapi Betina sebesar $64.59 \%$ dan pada Sapi Jantan $88.97 \%$ dengan ukuran citra masing-masing 64px dan 128px dengan model warna YUV.

Saran

1. Diharapkan untuk implementasi sistem dapat digunakan pada mobile, sehingga lebih memudahkan pada saat proses identifikasi.

2. Diharapkan pada penelitian berikutnya dapat menggunakan algoritma optimasi untuk mengoptimalkan parameter SVM dan sekaligus untuk seleksi fitur model warna. 


\section{DAFTAR PUSTAKA}

C. Cortes., V. Vapnik, 1995, Support-Vector Networks, Machine Learning, Vol. 20, No. 3, pp. 273-297.

I-Hong Jhuo, dan D. T. Lee, 2010, Boosted Multiple Kernel Learning for Scene Category Recognition. IEEE, International Conference on Pattern Recognition, ICPR (2010), page.3504-3507.

M. E. Tipping, 2000, The relevance vector machine. in Advances in Neural Information Processing Systems, vol. 12.

Ni Wayan Patmawati, Ni Nyoman Trinayani, Mahmud Siswanto, I Nengah Wandia, I Ketut Puja, 2013, Seleksi Awal Pejantan Sapi Bali Berbasis Uji Performans, Jurnal Ilmu dan Kesehatan Hewan, Februari 2013 Vol. 1, No.1: 29-33.

Noor A. Ibraheem, Mokhtar M. Hasan, Rafiqul Z. Khan, Pramod K. Mishra, 2012, Understanding Color Models: A Review, ARPN Journal of Science and Technology, VOL. 2, NO. 3, April 2012.

Peraturan Gubernur Bali Nomor 45 Tahun 2004 dan Perda No 2/2003 yang melarang bibit sapi bali betina keluar dari wilayah provinsi.

Rafael C. Gonzalez, Richard E. Woods, 2008, Digital Image Processing, Publication Date: 4 July 2008 | ISBN-10: 013505267X | ISBN-13: 978-0135052679 | Edition: 3.

Sethu Vijayakumar dan Si Wu, 1999, Sequential Support Vector Classifiers and Regression, Proceeding International Conference on Soft Computing (SOCO'99), Genoa, Italy, pp.610-619.

Soekardono, Chairussyhur Arman, dan Lalu Muhammad Kasip, 2009, Identifikasi Grade Sapi Bali Betina Bibit Dan Koefisien Reproduksi Sapi Betina Di Propinsi Nusa Tenggara Barat, Buletin Peternakan Vol. 33(2): 74-80.

Subhransu Maji, Alexander C. Berg, Jitendra Malik, 2013, Efficient Classification for Additive Kernel SVMs. IEEE, Transactions On Pattern Analysis And Machine Intelligence, Vol. 35, No. 1.

Takuya Inoue, dan Shigeo Abe, 2001, Fuzzy Support Vector Machines for Pattern Classification, Neural Networks Proceedings IJCNN'01, International Joint Conference on, 1: 14491454.

Zaher Hamid Al-Tairi, Rahmita Wirza Rahmat, M. Iqbal Saripan, dan Puteri Suhaiza Sulaiman, 2014, Skin Segmentation Using YUV and RGB Color Spaces, J Inf Process Syst, Vol.10, No.2, pp.283 299, June 2014 http://dx.doi.org/10.3745/JIPS.02.0002 